\title{
Strategy Identification For Sustainable Key Performance Indicators Delivery Process For Scholarly Publication and Citation
}

\author{
Sharanjit Kaur Dhillon, Roliana Ibrahim, Ali Selamat \\ Universiti Teknologi Malaysia, 81310 UTM, Skudai, Johor. \\ skdhillon84@gmail.com \\ Universiti Teknologi Malaysia, 81310 UTM, Skudai, Johor. \\ roliana@utm.my \\ Universiti Teknologi Malaysia, 81310 UTM, Skudai, Johor. \\ aselamat@utm.my
}

\begin{abstract}
Key Performance Indicator (KPI) is one of the performance measurement tools that assist someone in monitoring their performance against the target set by the management. Despite many implementations in delivering the KPIs, they are still unable to perform. It would involve investigating the current strategies undertaken by the management on how they deliver KPIs to academic staff in the Research Alliance of K-Economy (RAKE). This paper aims to investigate the problems of non-achieving KPI targets among academic staffs of RAKE. It also aims to highlight four areas of the strategy implementation that can be developed to deliver improved publication and citation outcomes for the targets set. The literature is reviewed and the targeted respondents' extensive experience in the issues related to scholarly publication and citation is drawn on. The four areas of strategic implementation are discussed as a guide. The paper finds that the imposed strategies can be applied to achieve the targets set by management if initiatives are taken by all levels of academic staffs as well as the involvement by the top management of the institution. The paper has immediate practical benefits for academic staffs of RAKE that it provides a four steps guide for improving the publication and citation culture among the RAKE staffs by utilizing knowledge management. This will result in greater outcome for the management of the University in maintaining the status as a Research University (RU) in Malaysia. It can be concluded that the strategies imposed can be applied at the beginners' level. Existing work has produced a sustainable KPI delivery process framework using Viable System Model (VSM) where it shows that there is a need to have integration among the university databases. However, this framework does not highlight details on how knowledge management contributes to the strategic initiatives of successful KPI delivery process.
\end{abstract}

\section{Indexing terms/Keywords}

Publication, Citation, Key Performance Indicators, Strategy, Viable System Model.

\section{Academic Discipline And Sub-Disciplines}

Management, Data and Information Systems, Knowledge Management

\section{SUBJECT CLASSIFICATION}

Data and Information Systems

\section{TYPE (METHOD/APPROACH)}

Literature Review and Survey.

\section{Council for Innovative Research}

Peer Review Research Publishing System

Journal: International Journal of Management \& Information Technology

\author{
Vol.3, No.3 \\ editor@cirworld.com \\ www.cirworld.com, member.cirworld.com
}




\section{INTRODUCTION}

Organizations cannot ignore the positive impacts of performance rewards on employee motivation. In order to balance motivating employees and encouraging knowledge management by knowledge sharing, it is important to find out which performance rewards could enhance knowledge sharing, or at least, have less negative impacts on knowledge management. The research problem revolves around the challenges in measuring the strategy implementation and the lack of administrative management's involvement through the exploration of the organizational knowledge process in this measurement. What are the factors that contribute to the failure of KPI delivery in scholarly publications and citations among academic staffs of RAKE-UTM.

Thus, the measurement of strategy implementation success through the tangible numbers of KPIs achieved can be complemented by this model. Most of the problem of non-achieving a KPI target is attributed to the academic staff, as either not publishing or not depositing their published papers in the right database. Those responsible should utilize a single database for the collection and deposition of the data. Moreover, the identification of key actors who influence the strategy implementation success amongst top and middle managers as stakeholders is also included in this model.

Contributing knowledge in the community, it comprises both the contextualization and interpretation of knowledge. This is a cost for the knowledge management, because knowledge contributors must take time and effort [2]. It takes time in knowledge coding, and after sharing knowledge, knowledge contributors will take more time to clearly explain or assist the knowledge seekers to have a better understanding of the knowledge provided [12]. Previous researches have suggested that the codification effort is a significant inhibitor for knowledge contribution $[2,12,16]$.

\section{REWARD TO EMPLOYEE}

The purpose of monetary rewards is to reward employees for their excellent job performance with financial means including cash bonuses, stock awards, etc. [8]. The purpose of non-monetary rewards is to reward employees through opportunities such as promotion and training opportunities [8]. [36, 37] study showed that people hoard knowledge because they fear that their subordinates would be promoted faster, which is actually the fear of losing promotion opportunity (i.e. a non-monetary reward).

Team-based rewards provide all members of a team with the same reward based on the whole team's performance [17]. Individual based rewards provide each individual with a reward based on his or her own performance [17]. One of the purposes of team-based rewards is to encourage cooperative behavior in the sense that individual team members strive for the best outcome of the whole team [14]. Studies have indicated that a collaborative organizational climate will improve knowledge sharing, whereas a competitive organizational climate will impede knowledge sharing [4, 27].

\section{Performance Measurement (PM) and Performance Indicators (PI)}

As the need of measuring performance of employees as reported by [7], it is also expected in KPI delivery process. In order to make organizations alert of the significance of KPI delivery, information system tools have to be put into place to quantify the reimbursement of those strategies to make them worth wile. According to [19], performance measurement can be:

- Used to help direct the allocation of resources: Where management will see through the organization and become aware of how and what to spend in an area;

- Used to assess and communicate progress towards strategic objectives: By taking all members of the organization along in order to have a viable strategy in moving the organization forward; and

Used to evaluate managerial performance: That is to also know if the top management are capable of fulfilling their roles as the leaders of the organization

Moreover, most literatures have sighted the importance of organizational leadership commitment to facilitate success [11]. To apply measurement tools in any organization, staff participation is essential [22].

\section{Concept of PM in Institutes of Higher Learning}

The need for every employee in institutions of higher learning (IHL) particularly academic staff of public universities in Malaysia to deliver his/her KPI targets has both positive and negative impacts. Experiences have shown that the employees could not deliver consequently because of many noteworthy factors affecting the delivery process. According to [3] institutions have to look for a passageway along which developmental activities can develop while enhancing quality of employees' life and ensuring the feasibility of KPI delivery processes on which both institutions and their employees are dependents.

IHL such as universities have employees whom are categorized into two, first the academic staff and second the nonacademic staff. An academic staff can be described as those in control of the processes of teaching and research in IHL. An academic staff is the primary actor in university, and can be defined as a Professor, Reader (Assoc Prof), Senior Lecturer, Lecturer and any members of staff of the university who are paid on academic related scales. The status of a university is subject to the strength of its academic staffs; also patrons are attracted to a university because of the composition of a university academic staffs [5].

From the above background, it is clear that for a constant upgrading of the overall institution as well as the performance of the academic staff needs to be measured and evaluated. Academic staff performance is demonstrated through the level of output and quality of teaching and research. One of the success factors of any university is the ability of its academic staff to show a high level of performance especially in areas relating to research and teaching. 
[35] defines academic staff performance as the ability of a staff to have creativity, self-discipline, ambition and motivation towards performing his duties. These entire factors are considered important to the university's objectives, and therefore become visible that most universities oblige strict measures on the performance levels of their academic staffs.

\section{KPI DEVELOPMENT}

According to[15] on the context of organizational performance measurement, KPIs have to be critically considered. Therefore the right strategic areas have to be considered in order to choose the right KPIs for the business. The choice of the right KPIs will initiate a discovery of where and how the organization is moving. Implementing KPIs successfully highly depends on their development [15], as well as require a systematic approach. This will require insider knowledge of all the organization departments that participated in the KPI development. [11] has described how organizations can be structured to have many units with their respective processes. This is an addition to [15] whom mentioned in the circumstance of development of KPI it's practical to use a method, which is in line with organizational structures.

It is important to set KPIs in which their efficiency can be measured. That is the value attached to a KPI should be able to reflect whether that KPI is effectively satisfying the goal of the organization or business. This shows why KPIs are required to be implemented into the information system in place in order to report to those concerned about the realtime progress of the KPI. [22] provides key steps in having a lasting and reliable KPIs:

- Start with experts that knows how to collect data on relevant strategic goals and he must have access to the organizational PI database.

- Have a a reporting mechanism on late delivery of services.

- Keep the top management informed about the status on ground in order to get high- level support.

- Develop a Balanced Scorecard (BSC) with a minimum of five to six result indicators.

\section{Scholarly Publication and Citation (SPC)}

Scholarly publications in higher institutions of higher learning have undergone rapid changes during the last two decades. The globalization of higher education and research institutions, university rankings and the emergence of electronic scholarly journals contribute to the changes these institutions are facing today.Scholarly Publication is an academic work in form of a written paper that has undergone a process of peer review by one or more referees in order to publish the paper in an academic journal. While Citations on the other hand is the use of references to support assertions and arguments by academic authors. Citations give credit to other authors and also provide readers of an academic journal with more information on the subject being discussed in the paper [34].

Scholarly publications in academic institution has become very signifcant in a way that even staff promotion is entirely based on it, as the popular saying of publish or perish which according to [33], the phrase emphasizes the importance of research in any academic institutions. But even with the importance of scholarly publication in academic institutions, a lot of diffculties are faced by academic staffto meet their targets, such as non-involvement in the design of their key performance indicators, lack of committed leadership to encourage them, lack of facilities and competent supportive staff[18]. These problems lead to demoralization of academic staff which needs to be addressed

\section{Evaluation on the success of KPI Implementation}

$[30,14]$ has defined KPIs as a tool used to measure the success or compliance in an organization. In many IHL, KPIs has been selected as a performance measurement tool with a metric value usually attached. And these KPIs allow organizations to see areas it is executing well and what areas require improvement [21, 40]. As a self-assurance tool, KPIs implementation has proven to be effective in IHL.

According to [24] 70 per cent of balanced scorecard implementation fails. The author goes on to argue that there are two key reasons why KPI success measurement fail. The first is that measurement systems are often poorly planned. The second is that they are difficult to implement due perhaps to (politics, infrastructural issues, and loss of focus). KPI implementations can also suffer from the same issues. The KPI literature suggests that successful performance measurement depends on how well these KPIs are planned [13, 25, 39]. Key performance indicators can be:

- $\quad$ Process-based (e.g. compliance with guidelines),

- $\quad$ Activity-based (e.g. dollars spent, numbers employed)

- Outcome-based indicators (e.g. goals achieved, success of services)

KPIs are particularly useful when they are associated to policy concerns or outcomes. KPIs can be categorized in a number of ways [39], some of which are:

- Quantitative KPIs: The amount of a product or service

- Qualitative KPIs: Structured perceptions or structured feedback

- Cost efficiency KPIs: The unit cost of achieving a specified amount of service 
- Cost effectiveness of KPIs: The unit cost of achieving a specified amount of service to a designated level of quality

- Timeliness / Responsiveness KPIs: The time taken to perform a service, or the number of transactions or products within a time cycle

- Work team productivity KPIs: The amount of output of a workforce unit or group

\section{RAKE UTM}

As established in February 2009, K-Economy Research Alliance also known as RAKE was formed with the intention of strengthening research and consultation activities by focusing the activities towards higher impact, better and more industry-relevant programs. RAKE is built upon a strong association of existing centers of excellence, laboratories, forma and informal groups of individual professors and established research groups within UTM. Up to date, RAKE has about 551 research members within 35 research groups and 2 center of excellence (COE). Research members are formed from various disciplines especially from ICT, management, education, Islamic studies and geo-information, which makes RAKE a very multidisciplinary alliance. This fits very well with the multidisciplinary nature of the K-Economy.

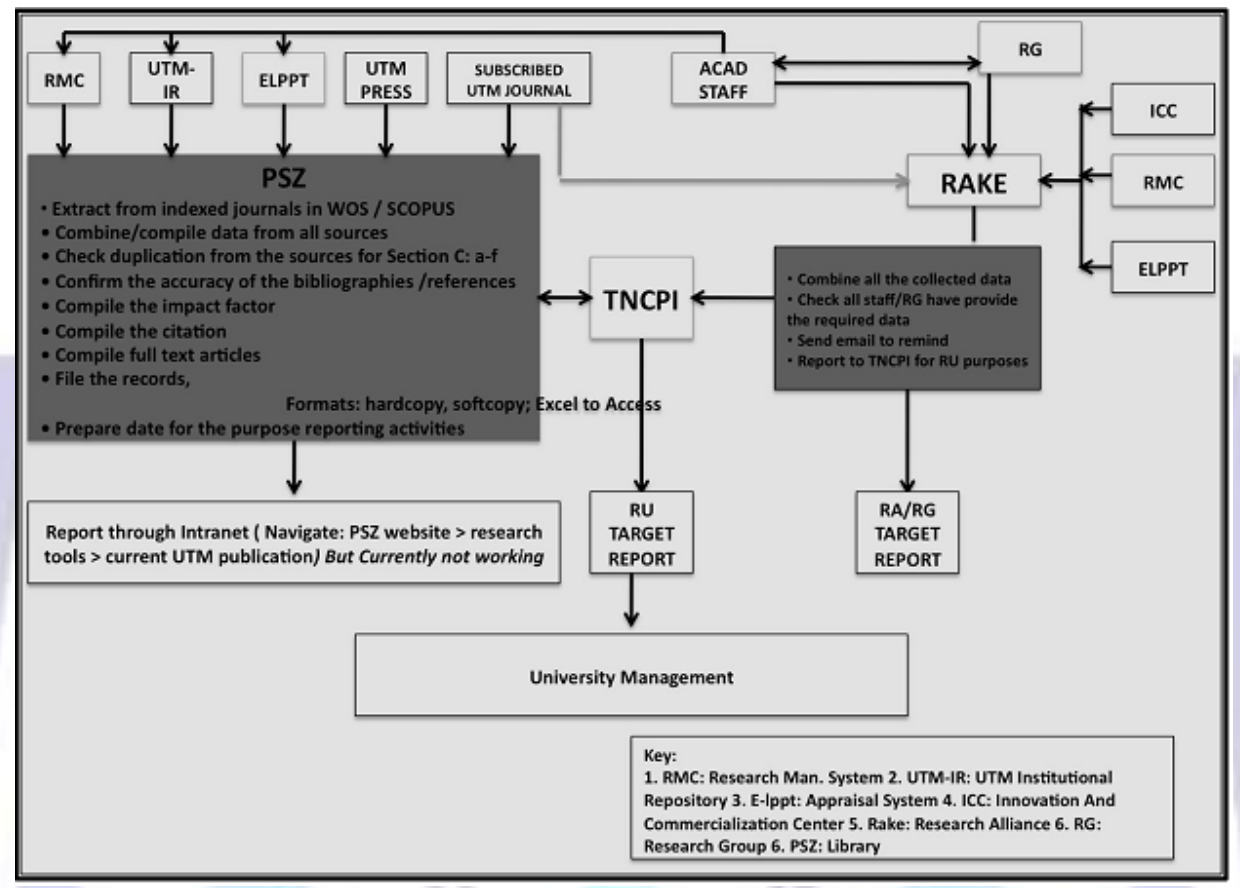

Fig 1: Stakeholders Participation on Scholarly Publication in UTM

UTM implemented KPI delivery as one of the strategic initiatives to improve the overall performance of the academic staff towards achieving the university's strategic goals. The delivery process is based on targets to be achieved by all applicable stakeholders. Even though the KPI delivery process is simple in its objectives, its execution and implementation involves different efforts from different group of actors such as Research Management Center (RMC), Research Alliance (RA), Research Group (RG) and individual academic staff. These players have their own potential, targets and prospects. Moreover, the players' role to the required target in the KPI delivery process varies at different level of the organization. Figure 1, shows the current stakeholders' participation in the KPI delivery process of scholarly publications and citations.

\section{UTM's Policy on SPC}

According to [21], the benefts of implementing KPIs in academia are manifold, they assist in creating a performance-based work culture, by providing additional visible criterion for annual appraisal as well as endorsement plus allocating apparent objectives meant for individuals to endeavor for it. In UTM, the approach used which is Balanced Scorecard is to make sure that the performance targets of staffs are associated with the ones of the university.

The policy of using KPI for the annual appraisal of academic staff was introduced in 2009. And these KPIs were developed and each academic staff have to attain above $80 \%$ in each of the KPI. The criterion utilized are leadership teaching, supervision of postgraduate, research input and output, personal quality, professional services, as well as other contributions. As for endorsement or promotion, a special weightage is employed. For instance, an academic staff in the scale of DS45 carries the weightage of $60 \%$ for teaching contrast with senior lecturer who carries 45 percent.

Research publication KPIs of UTM does consider both SCOPUS and ISI. This is for citation and also indexed journals. Particular importance is specifed to the cumulative impact factor and distinguish between high, medium and low impact journals. In order to tackle the complexity the academic staffs from the social sciences is facing to publish in ISI indexed journals, UTM has set them a lower target. While for papers written with co-authors, it does not differentiate among first and second authors, with each member receiving the equal score. 


\section{METHODOLOGY}

The authors used both mixed method approach by combing quantitative and qualitative methods. Using multiple approaches can capitalize on the strengths of each approach and offset their different weaknesses [9]. The scholarly publication and citation is clearly relevant for universities with the status of Research Universities to sustain their ranking and status among the other universities regardless in the national or international level. The authors were given longitudinal access to study the deployment of publication and citation targets at the UTM.

Field work and data collection were undertaken to identify the main aspects of the study. On the basis of qualitative data analysis and collection we formulated our research interest as: investigating the current strategies undertaken by the UTM management on how they deliver KPIs to academic staff in the Research Alliance of K-Economy (RAKE) and to investigate the problems of non-achieving KPI targets among academic staffs of RAKE. To pursue this line of inquiry we have built on our own studies, the existing outsourcing literature, and lessons learned from academic staffs of RAKE. The study also aims to highlight four areas of the strategy implementation that can be developed to deliver improved publication and citation outcomes for the targets set.

Data collection among the RAKE staffs has been carried out using direct observation, open-ended interviews, and restricted internal RAKE documentation. Interviews were done among the targeted staffs to identify the key strategies. We carried out interviews with senior lecturers, Professors and Associate Professors within the RAKE community. Multiple sources of evidence have been used to validate the findings.

\section{PROPOSED METHOD}

In this section we propose a diagnosis framework that will allow the discovery of factors affecting a KPI delivery in institutions of higher learning (IHL). This framework is build upon viable system model (VSM) [29, 32, 31], one of the most widely used and well-regarded diagnosis tools. Yet some systems thinking literatures have recognized some weaknesses with the VSM $[20,23]$. It was found that VSM is a theoretical replica that does not have a solid physical existence and furthermore it incompetently gives results if used autonomously.

While we conserve the methodological force of VSM, we will as well endeavor to correct some of these weaknesses by combining it with other diagnosis approach. We used Alderfer Model [1], who proposes three stages of organizational diagnosis; entry, data collection and feedback. But in our approach, we have changed the sequence of Alderfer model by featuring VSM, which will as well match the Alderfer models' weakness of missing coordinating purpose between the model fundamentals.

The new model/framework will be poised of four phases (Figure2) and all of these phases have a commencement and an end with some overlapping, this means there is some VSM activity, data collection and feedback during the entry phase, some entry, VSM activity and feedback during data collection, some entry, data collection and feedback during VSM activity and some entry, data collection and VSM activity during feedback. The following paragraphs enlighten the components of the framework.

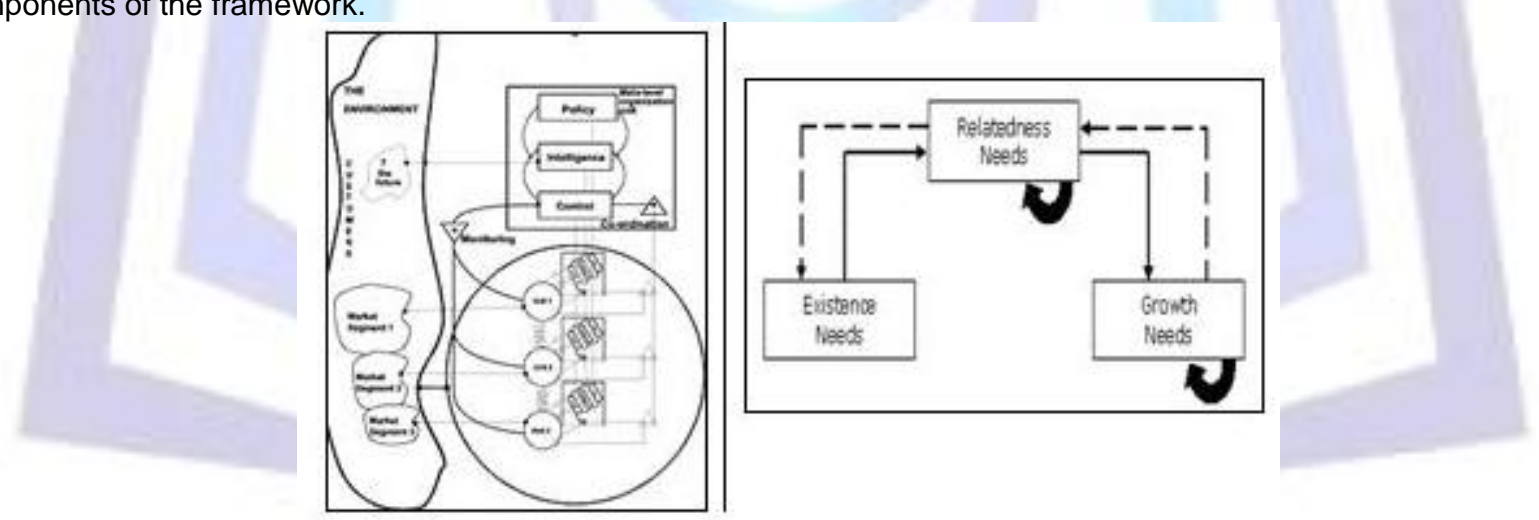

Fig 2: Viable System Model and Alderfer Model

\section{A. Entry}

This phase is akin to [26] VSM diagnostic process. In [21] the analysis is divided into two; the system discovery and system analysis. In system identification, the target system in which the analysis is necessary will be determined as in the system analysis, corresponding of the VSM framework will be done to the system in focus. Thus the entry phase in our framework begins when the participating system (system in focus) is determined. And this is regularly through document analysis, observation or consultation with the clients [1]. It is usually at this stage that at times hypotheses are generated to let thorough analysis of the situation. We can observe that in entry, some elements of data collection have appeared. It is also at the entry phase that the viability of the analysis is determined, since the researcher as well as the organization (client) will agree and offer access to their staff and confidential resources. At the end of this phase, a clear understanding of the task ahead is expected as well as revisits to areas not clear are made.

\section{B. Data collection}

This phase begins with the option of methodology in which all related data will be collected [1]. Any approach of data collection can be employed, either qualitative, quantitative or mixed method, depending on the system in focus being diagnose. This phase require formulation of questions to be asked in either the interview or survey. The researcher is 
tasked to analyzed the data collected with the objective of making all the VSM subsystems have featured. It is clearly at this stage that problematic areas will begin to appear after the analysis.

\section{Viable System Model (VSM) activity}

In this layer, the (VSM) is used as a template [6] to guide the classification of the factors influencing a particular process. VSM is a tool introduced by Stafford Beer [29, 32, 31], which shows how system can be able of independent existence. The VSM is build upon three principles; Cybernetic, Law of requisite variety and Recursion [10]. The cybernetic principle explains how systems are associated as one component sharing resources. The law of requisite range provides the ability of systems to be self sustaining by obliging any changes from the surroundings [10]. And recursion shows how any viable system is contained and it contains another viable system, example of a Russian doll. With these three principles, the VSM operates based on five major subsystems (implementation assumed as system 1, coordination assumed as system 2 , control and audit takes system 3, intelligence serves as system 4 and policy as system 5), which are synergistically connected to provide a self sustaining system. The failure of any of this subsystem will guide to a breakdown of the complete system. Hence, prior to using the VSM framework, data collection as well as organizational analysis is vital from the system in focus. This will reveal the key goals of the organization as well as the entire flow of processes in the organization. In the framework, two VSM activities will be noticed; this is showing the recursive nature of the procedure and the overlapping of phases in the framework.

\section{Feedback}

Feedback phase is concerning of communicating the result of the overall diagnosis to the related authority with list of prioritized problems. This phase also will decide the agreement of the organization or stakeholders on the proposed way out given by the researcher. The results obtained from the table of outcome will determine which of the VSM subsystem is facing challenges based on the identified factors and that will signify where action need to be taken in order to have a viable process.

\section{Knowledge Management and the Importance}

The knowledge that is in the individuals and organizations themselves provides the framework in which they decide alternatives from enormous variety of possibilities. Normally, self-knowledge is mediated by the society and language in which deliberations occur and the degree to which it is likely to incorporate a variety of perspectives and models to facilitate act as a decisive unit. Big organizations which have gotten into difficulty frequently have done so since they behaved as if their range and their capability to do anything doomed they could do everything.

Current management thinking has been paying attention on reining in this trend: shaping foundation competencies and focusing on them, considering how society and principles uphold processes and practices, and learning to make behavior all through the organization logically and reliably [28]. Getting a handle on the social and technical assets of knowledge in the organization is an essential footstep.

Definitely knowledge management is a big picture subject. Just as undoubtedly, deficiencies here expose the organization to the risk of not recognizing opportunities or threats. If it is not known where knowledge possessions are and how they are being utilized, much of their likely significance may be shattered.

\section{STRATEGY IMPLEMENTATION}

The authors identified that the successful scorecard implementations were those where the senior lecturers was affianced with publication culture from the beginning. Our proposed approach focuses attention on the beginners' level factors that drive success towards publication and citation and came up with a four-phase balanced scorecard approach as in Figure 3. The outline of the process that was identified is to give in a good start for the implementation of publication culture for the RAKE in UTM.

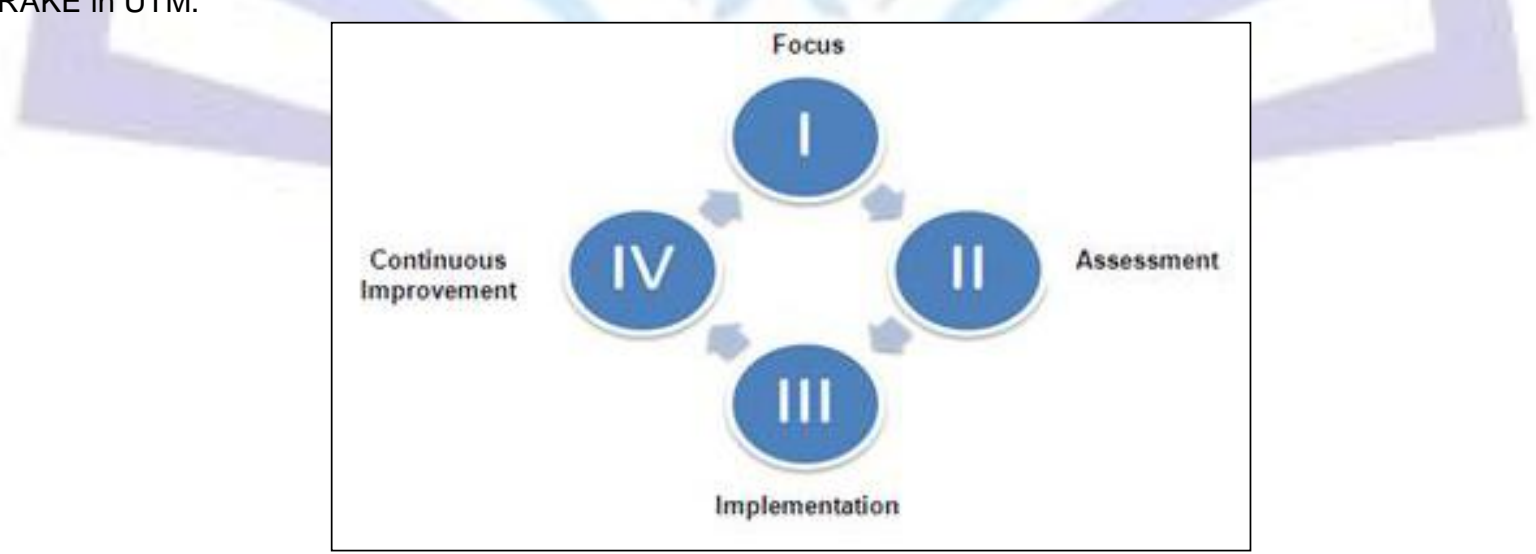

Fig 3: Four Phase Balanced Scorecard Approach

Phase I: Focus

Step 1. Define Strategy Precise strategy is the base for performance measures. RAKE UTM will answer three fundamental strategy questions:

- What are the most important objectives for the research alliance to achieve?

- What "driver" results - for example, targets, — are critical to achieve these objectives? 
- What "drivers" - for example, leadership, training, diversity, and values - impact performance on these driver results?

The authors help answer these questions through a review of one-on-one interviews, strategy discussions. This is a survey tool to swiftly:

- Illuminate the strategy.

- Parallel with senior team on strategy issues.

- Discover barriers for room of upgrading.

The subsequent step is habitually implementing a balanced scorecard, because balanced scorecards are an outstanding medium for a specific strategy, communicating it to the organization, aligning people around the strategy, and ingraining the strategy into daily decision-making.

\section{Phase II: Assessment}

Step 2. Develop new driver and performance measures RAKE UTM will have to develop new measures as needed. This may include an employee survey that indices on issues that predict better publication outcomes. It covers three areas that RAKE has identified as predicting end result.

- Wherever possible, your existing measures will be incorporated to ensure continuity.

- RAKE selects survey questions based on its extensive knowledge of the measures that accurately predict the academic staffs' performance.

- As the survey is tested over time, the measures are refined to best predict performance among RAKE staffs.

Step 3. Apply new balanced scorecard measures

RAKE will apply new measures, using tools which make them easy to understand and implement.

Step 4. Analyze and report

Analysis is a critical element of strategic assessment. At this step in the process, RAKE will:

- Performs linkage analyses to identify the relationships between academic staffs' data and their performance in key areas such as productivity in publication, and their performance in research related agendas. These analyses will identify the people issues that have the greatest impact on their performance. The result is a People Performance Index that predicts performance in the respective Research Alliances.

- Indicates the performance development that can be anticipated from your investment in people management by telling how much improvement can be realized in the outcomes from targeted levels of improvement.

Phase III. Implementation

Step 5. Implement improvement plans

The measures need to be taken at this phase are to:

- Set priorities for action based on strategy, newly identified people drivers of business performance, and comparisons to high performing organizations.

- Set specific performance targets and timetables.

- Assign accountabilities for improvement efforts.

- Map existing initiatives against priorities, and consolidate action wherever possible.

- Develop plans for specific improvement initiatives.

This process embeds the balanced scorecard and its measures in the day-to-day working life of the academic staffs in RAKE, spreads awareness of the impact of effective people management, and initiates the necessary change processes. Specialists in organizational change and performance improvement can be applied to help RAKE with implementation. For example, higher authorities in RAKE then can:

- Train people to interpret people measures and to facilitate follow-up sessions.

- Facilitate follow-up sessions, either on our own or teaming with your people.

- Design initiatives to address people issues.

\section{Phase IV. Continuous Improvement}

Step 6. Track improvement

Continuously track performance on their people measures is an essential step. Continuous tracking measures the shortterm brunt of improvement efforts and identifies rising issues promptly. RAKE can have a pulse tracking program - speedy, episodic surveys of a RAKE population is a cost-effective way to track performance improvement on a specific issue by administering the issue in question to a targeted sample of the work force. Pulse surveys typically use a few items rather than comprehensive questionnaires.

They may be aimed at a cross-section of the entire organization, but they are often focused on a specific segment of the work force in which targeted change efforts have been implemented. A pulse survey administered via this quick turnaround approach can provide instant feedback on progress on key issues and enables management to implement needed course corrections.

Step 7. Continuous improvement through balanced scorecards

By re-embarking on the cycle once again, and cascading it down (or across, or up) to other levels, while continuing to track key measures and re-set goals, RAKE can create and support continuous improvement programs which will provide a long-lasting competitive advantage. This can then be adapted to other Research Alliances in UTM to be tested for the improvement in publication and citation to meet the targets set by the university.

\section{HOW TO GET THERE?}


With more than 1300 academic staffs in UTM in the year 2012 (see table 1), it is possible to achieve the target of publication as targeted by the VC of UTM. The simplest way to achieve this target is by assigning 1 impact factor for each academic staff. This can be achieved if all the academic staffs can implement the below calculator for their academic appraisal:

1 staff with 1 PHD student $=1$ SCOPUS journal

1 academician with 1 PHD student $=>1 \mathrm{IF}=1 \mathrm{IF}$.

Thus with 2000 academician who has at least 1 PHD students $=>1 \mathrm{IF}=1 \mathrm{X} 2000=2000 \mathrm{IF}$

Therefore it is possible with 4000 over students (in year 2012) to help to produce with the staffs at least 1 IF journal to meet the target of the university. This can be good practice as in the year of 2015 ,

Table 1. Facts and Figures as in September 2012 (Adapted from: www.utm.my (08 Nov 2012))

\begin{tabular}{|c|c|c|c|}
\hline $\begin{array}{c}\text { Academic } \\
\text { Staffs }\end{array}$ & Total & $\begin{array}{c}\text { Graduate } \\
\text { Students }\end{array}$ & Total \\
\hline $\begin{array}{c}\text { Academic } \\
\text { Staffs }\end{array}$ & 2077 & $\begin{array}{c}\text { Graduate/Post } \\
\text { graduate } \\
\text { Student }\end{array}$ & 12739 \\
\hline $\begin{array}{c}\text { Full time } \\
\text { International } \\
\text { Academic } \\
\text { Staffs }\end{array}$ & 165 & $\begin{array}{c}\text { International } \\
\text { graduate } \\
\text { Student }\end{array}$ & 4442 \\
\hline $\begin{array}{c}\text { Visiting } \\
\text { International } \\
\text { Academic } \\
\text { Staffs }\end{array}$ & 150 & PhD Student & 4366 \\
\hline $\begin{array}{c}\text { Outbound } \\
\text { Visiting } \\
\text { Academic } \\
\text { Staffs }\end{array}$ & 802 & Master & 8373 \\
\hline $\begin{array}{c}\text { Academic } \\
\text { Staffs with } \\
\text { Phd }\end{array}$ & 1100 & & \\
\hline
\end{tabular}

the target to achieve is estimated 6000 for Indexed Publication (SCOPUS) with estimated 1800 staffs with PHD and 5000 PHD students.

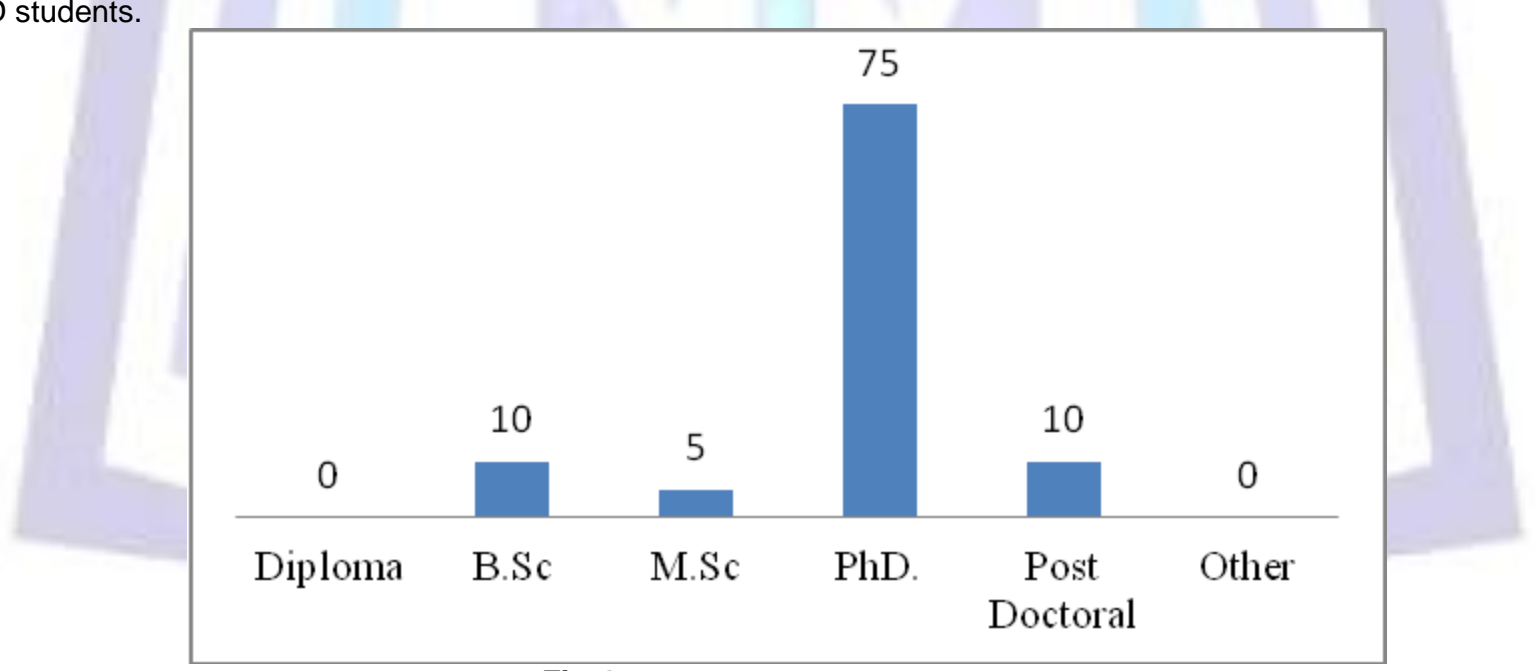

Fig 4: Academic Staffs' Qualification

Based on a survey participated by RAKE members, many are still unaware about the targets being mentioned by the ViceChancellor of UTM [38]. In his book, [38] is being mentioned about all the targets to achieve the world class university by year 2020. According to the statistic of the survey only $15.79 \%$ of the respondents actually read the content of the book and this is also identified as one of the factor why the targets are not being accomplished by the university. With $75 \%$ of Ph. D degree holders (See Figure 4) and $40 \%$ of staffs with more than 11 years of service in the university (See Figure 5), the strategy of publishing to meet the target can be accomplished easily.

On the other hand, many academic staffs felt demoralized with the targets being set for them for the portion of research as they feel it is heavy burden with the admin workload, research, teaching and supervision of students. Therefore, $65 \%$ of the respondents feel that publication is only their responsibility as an academician, where as $5 \%$ sees publication and citation as to increase the citation and h-index and another $5 \%$ wants to do it for the sake of job promotion. (See Figure 6) One of the strategies being imposed by the respondents was to write journals with co-authors from various designation levels. This involves from the highest rank such as Professors and Assoc. Professors to Senior Lecturers and Lecturers and not forgetting the tutors as well as the librarian as writers. This way, the tacit knowledge can be shared among all levels of academic staffs and the process of knowledge management and knowledge sharing can take place. The 
phenomena to transfer tacit knowledge can be implemented effectively when it is done face-to-face in workshops organized by the respective research alliances.

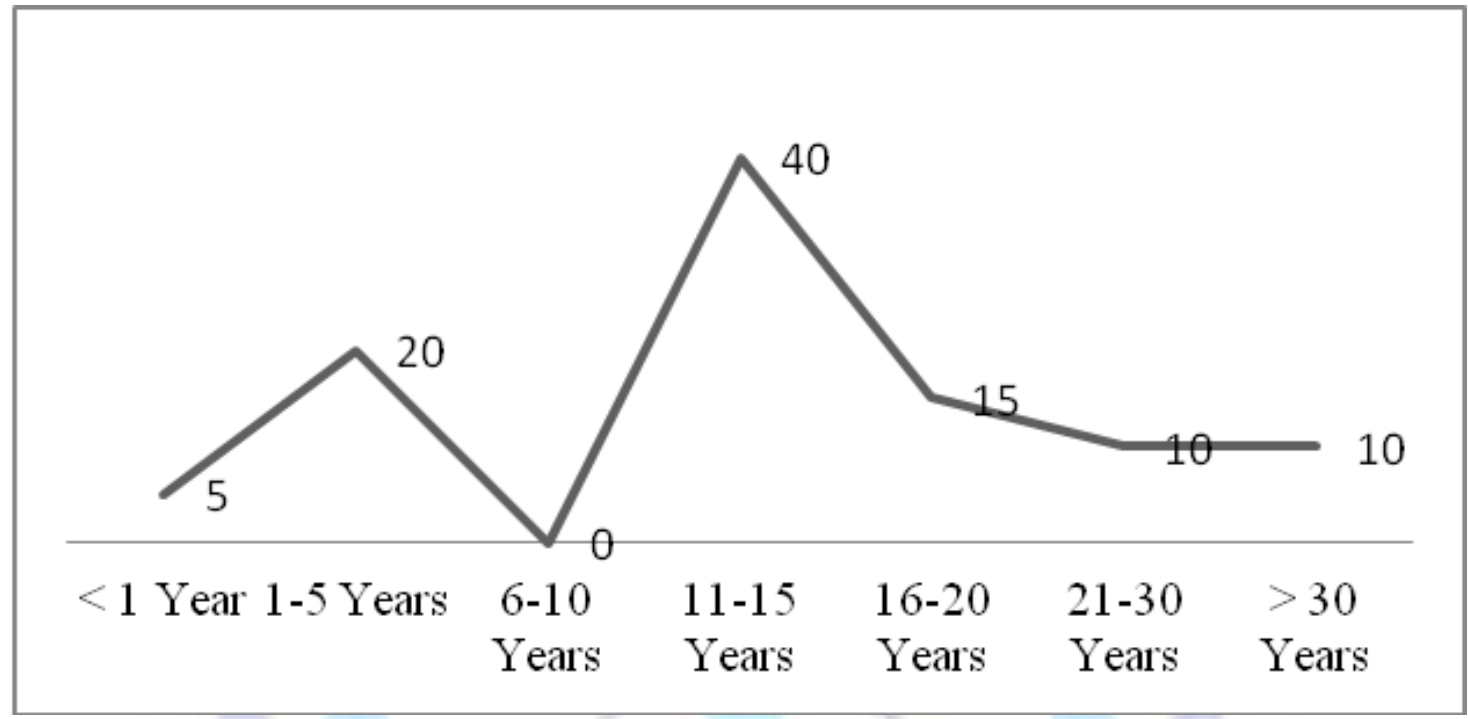

Fig 5: Years of Service

Even though with a big number of academic staffs in UTM, it is unimpressive that the target is not fulfilling the goals. One of the many reasons given by the respondents was UTM can hardly achieve the targets because there are social sciences academic staffs who are facing the problem with the indexed publication. It'd be much clearer if he number could be fairly divided for engineering and non engineering staffs. Those academic staffs from the social science background and Islamic studies facing the problem are affected with the KPI delivery for not reaching their performance appraisal due to this reason. Lack of culture in publication among the academician is also identified as one of the reason behind the unachievable target.

Due to this reasons, workshops and seminars need to take place to implant the culture or writing among the research alliance members. Many imposed that training in writing for research methods and advance data analysis need to be conducted by professionals. Besides that, invite reviewers and editors from well known journal publishers to give them overview of the reviewing process to get the journals published in high impact factor papers. Many gets demoralized when the reviewing process takes a very long time and time to publish paper takes more than a year. By having peer-reviews in workshop by good writers, this issue can be resolved or at least minimized.

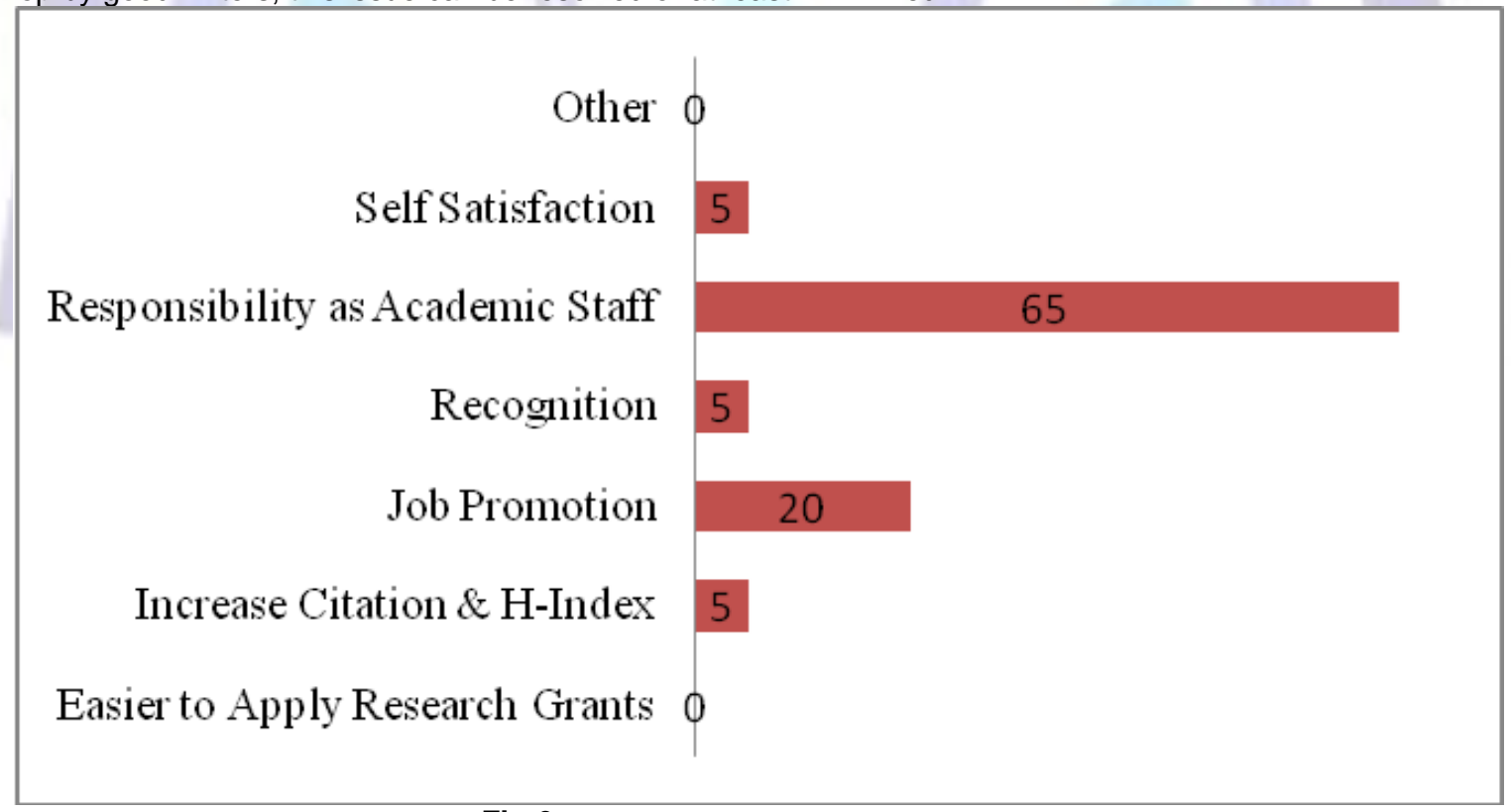

Fig 6: Motivation to Publish in IF Journals

Mobilizing the research students from postgraduate level in order to achieve the target is also a good strategy imposed. Training and constant guidance need to be given to the research students so that they can publish high impact factor papers and at the same time helping to contribute for the university. With the multi discipline background such as the student, supervisor and co-supervisor (if any), the results can be more satisfactory since the mentor-mentee process takes 
place to get a perfect piece of work to be delivered. Collaboration with well known professors in the areas (identified by each faculty/RG) preferably from established institution. Collaboration with industry (like in Korea; where Samsung finances PG studies to solve industry's problems and needs).

\section{CONCLUSION}

Strategy initiatives can be one of the success factors for achieving the targets but it always relies on the encouragement and support from various parties to reach the goals. From this study it can be concluded that there are many strategies that can be implemented to have scholarly publication and citation targets achieved by UTM if all parties take parts and work for it. The strategies can be applied stage by stage from the beginners level to the intermediate and lastly to the professional level. Among the proposed strategies were to invite as many as possible editors from high impact journals to establish relationship with UTM staffs; which can be done at the beginners' level. Bring the culture of research through seminars and competitions. Incentives for local publications and non IF journals as means of polishing writing skills and also not to abandon these publications for the sake of knowledge growth. Make publication as an academic culture and main responsibility of lecturers. These steps can be categorized in the intermediate level of strategy implementation. As for the professional level, have both local and international collaboration with the industry as well as the reviewers and editors. Not forgetting the collaboration among the highest to the lowest designation academic staffs in the institution.

\section{ACKNOWLEDGMENTS}

The authors would like to thank the management of Universiti Teknologi Malaysia (UTM), the Faculty of Computer Computing (FC) and The Research Management Center (RMC) for the support in making this study a success.

\section{REFERENCES}

[1] Pistore, M., Leymann, F., Kazhamiakin, B., Karastoyanova R.. Adaptation of service-based applications based on process quality factor analysis. In The 2nd Workshop On Monitoring, Adaptation And Beyond, 2009.

[2] Rosenberg, P., Brandic, F., Leymann, I., Dustdar, F., Wetzstein, S. B. Monitoring and analyzing influential factors of business process performance. In The 13th IEEE International Enterprise Distributed Object Computing Conference. Edoc, 2009.

[3] Tejeida, R. Morales, O. Badilo, I. A viable system model approach to enterprise resources planning system. ISSS, 52, 2008.

[4] Beer, S. Diagnosing the System for the Organizations. John Wiley and Sons, Chichester, 1959.

[5] Ken, P., Mills, J., Bourne, M. The success and failure of performance measurement initiatives perceptions of participating managers. International Journal of Operating and Production Management, 22(22), 2002.

[6] Tejeida, P., Morales, M., Briones, J. Towards the evolution of the tourism's conceptual system. International Society for the Systems Sciences, 2009.

[7] Brocklesby, J. Using the viable systems model to examine multi-agency arrangements for combating transnational organized crime. Journal of Operational Research Society, 2011.

[8] Beer, S. Diagnosing the system for organizations, 1985.

[9] Bernadette, R., Alan, W., Charlotte, C., Richard, F.. Mixed research methods. Sage Publications Inc, 2004.

[10] Laws, A., Kenan, F., Taleb, B., Sterrit, R. Model-based self-managing systems engineering. In Proceedings Of Software Engineering Workshop, 2005.

[11] Laws, A.G., Keenan, F., Taleb A., Bustard, D.W., Sterrit R. Integrated use of ssm and vsm in autonomic system design. 2007.

[12] Espejo, R. The Viable System Model: A Briefing About Organizational Structure.Chichester. 2003.

[13] Fiksel, J. Toward a sustainable cement industry sub study 5: key performance indicators. World Business Council for Sustainable Development, 2002.

[14] Jackson, M., Flood, C. Creative Problem Solving. Total Systems Intervention. John Wiley And Sons, New York, 1991.

[15] Galleto, M., Maisano, D., Fraceschini, F. Management by measurement, 2007.

[16] Micheal, F., Francis, H., Patrick, K. Supporting crime detection and operational planning with ssm and vsm. Journal Of System Research And Behavioral Science, 26:11, 2008.

[17] Mallery, P., George, D. PSS for Windows step by step: A simple guide and reference. Allyn, Bacon,Boston, 4th edition, 2003

[18] Gideon, E.C. Open access repositories in academic and research institution in Nigeria international research centre, 2008.

[19] Hoverstadt, P. Fractal Organization: Creating Sustainable Organizations with the Viable System Model. 2008.

[20] Jackson, M. System Approaches To Management. Kluver, N.Y USA, 2000.

[21] Jung, K.Y.. The Research of Performance Measures and Analysis of Public Project about Application of RFID Technology. PhD thesis, 2007.

[22] Mietchen, D., Georgiev, T., Stoev, P., Sautter, D., Agosti, A., Plank, M., Balke, L., Heandrich, T., Erwin,L., Penev, G. Interlinking journal and wiki publication through joint citation: working examples from zookeys and plazi on species. Zookeys, 90:1-12, 2011.

[23] Leonard, A. Integrating sustainability practices using viable system model. ISSS, 25:9, 2008.

[24] Bourne, M. Neely, A. Why measurement initiatives fail. Measuring Business Excellence, 4(4):3-6, 2000.

[25] Ozkan, E. Key Performance Indicator Portfolio. AIS AHEAD Programme. European Organisation for the safety of air navigation, Brussels, 2001.

[26] Albaum, D.S., Green, G.P., Tull, E.. Research Methods For Marketing Decisions. Prentice Hall, 5 edition, 1993. 
[27] Patrick, H. The Fractal Organization: Creating Sustainable Organization With The Viable System Model. 2009.

[28] Hamel, G., Prahalad, C.K. The core competence of the corporation. Harvard Business Review, 2000.

[29] Harnden, R., Walker, J., Espinosa, R.H. A complexity approach to sustainability. Stafford Beer revisited. European Journal Of Operational Research, 187, 2008.

[30] Zambuni, S. A., Flood, R.L Viable systems diagnosis. 1. application with a major tourism services group. Systemic Practice and Action Research, 3(3):225-248, 1990.

[31] Yussof, M.B. Rodina, A. A viable approach to tackle complex enterprise situation for SISP. Malaysian Journal of Computer Science, 19(16), 2006.

[32] Bean, C. P., Jacobs, S. Fine particles, thin films and exchange anisotropy, volume 3 of Magnetism. New York, 1963.

[33] Beer, S. The Heart of a Firm. John Wiley and Sons, Chichester, 1979.

[34] Beer, S. Brain of a Firm. John Wiley and Sons, Chichester, 1981.

[35] Gomes, J. Shale, D. Performance indicators and university distance communication. Urbana, 1998.

[36] Beer, S. The heart of the firm, 1979.

[37] Ujang, Z. Enculturing innovation:the seven pillars, 2010.

[38] Ujang, Z. New Academia.UTM As A Global Brand (The 2012 New Year Address by the Vice Chancellor). Penerbit UTM Press, 2012.

[39] Prior, M., Vial, D. Use of key performance indicators in the planning and management of public open space. In PLA Conference., Perth, 2003.

[40] Shelke S.M., Jadhav, V., Khaparde, S. Citation analysis of university., 2011.

\section{ABOUT THE AUTHORS}

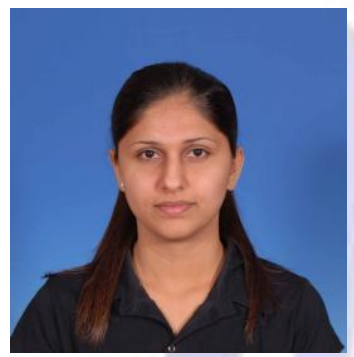

Sharanjit Kaur Dhillon

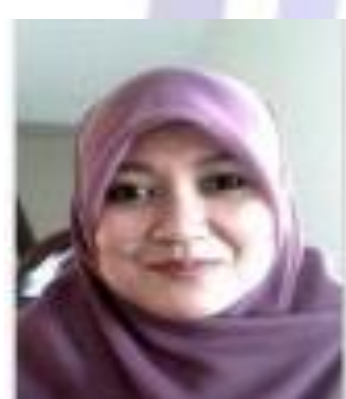

Roliana Ibrahim, Dr.

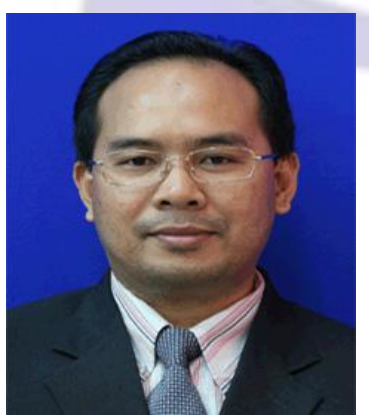

Ali Selamat, Prof. Dr.
Sharanjit Kaur Dhillon is currently a Ph.D candidate in Information System department. The research area is on Knowledge Management. The scope of the study being researched is on Key Performance Indicators Delivery Process for Scholarly Publication among the academic staffs of university. She attained her Masters Degree from Universiti Teknologi Malaysia in Information Technology (Management) in the year 2010 and her B.Sc degree in Computer Science majoring in Information Systems from the same university in the year 2008. She has 2 years teaching experience and among the subjects taught are Human Computer Interaction, Database Management and Management Information System

Roliana Ibrahim is a senior lecturer at the Faculty of Computing, Universiti Teknologi Malaysia. She has been servicing UTM for more than 10 years after a few years experience working as a system developer in the industry. She received her PhD in System Science from Loughborough University and currently a member of Software Engineering Research Group. Her research interests are the adoption of system thinking methodologies and ontology as innovative solutions for complex systems integration and development, data warehousing and data mining. She has been recognized by The Oracle Certification Program As Oracle Database $11 \mathrm{~g}$ Administrator Certified Associate. In addition, she is also recognized as Microsoft Certified Professional Developer (MCPD) in ASP.NET Developer 3.5 and Microsoft Certified Technology Specialist (MCTS) in SQL Server 2008, Database Development.

Ali Selamat is a Professor at Software Engineering Department, Faculty of Computing, Universiti Teknologi Malaysia (UTM). He obtained a Doctor of Engineering from University of Osaka Prefecture, Japan, Master of Science degree in Distributed Multimedia Interactive Systems from Lancaster University, United Kingdom, Bachelor of Science in Information Technology from Teesside University, United Kingdom, and Diploma in Computer Science from UTM. He received a certificate in Japanese Language Studies from Osaka University, School of Foreign Studies, Japan, in 2000. He teaches the undergraduate and postgraduate students for subjects such as Software Engineering, Software Architecture, Software Technology, Human Computer Interactions, Research Method in Computer Science and Theory of Computer Science. His research interests include Software Engineering, Software Agents, Web Engineering, and Information Retrievals, Artificial Intelligence and Softcomputing 